\title{
Wild Cinchona (Neolamarckia cadamba) - Bioactivities of a Medicinal Plant of Bangladesh
}

\author{
Faiza Tahia', Mohidur Rahman², Marzia Bilkiss', Md. Al Amin Sikder ${ }^{1}$ \\ and Mohammad A. Rashid ${ }^{1}$ \\ ${ }^{1}$ Phytochemical Research Laboratory, Department of Pharmaceutical Chemistry \\ Faculty of Pharmacy, University of Dhaka, Dhaka-1000, Bangladesh \\ ${ }^{2}$ Department of Pharmacy, State University of Bangladesh, Dhaka-1205, Bangladesh \\ ${ }^{3}$ Department of Plant Pathology, Faculty of Agriculture, Bangladesh Agricultural University \\ Mymensing, Bangladesh
}

Received: December 27, 2015; Accepted: January 28, 2016; Published (Web): February 17, 2016

\begin{abstract}
The methanol extract of bark of Neolamarckia cadamba (Roxb.) and its organic and aqueous soluble partitionates were subjected to assays for antioxidant, cytotoxic, thrombolytic, membrane stabilizing, antimicrobial and analgesic activities. In the DPPH free radical scavenging assay, the pet ether and carbon tetra chloride soluble partitionate of the methanolic extract demonstrated the highest free radical scavenging activity with $\mathrm{IC}_{50}$ values of $60.46 \mu \mathrm{g} / \mathrm{ml}$ and $78.58 \mu \mathrm{g} / \mathrm{ml}$, respectively. On the other hand, the carbon tetrachloride and pet ether soluble fractions displayed the potential lethality to brine shrimps, having LC50 of 7.24 and $7.89 \mu \mathrm{g} / \mathrm{ml}$, as compared to standard vincristine sulphate ( $\mathrm{LC}_{50}$ value of $0.45 \mu \mathrm{g} / \mathrm{ml}$ ). During assay for thrombolytic property, the carbon tetrachloride and aqueous soluble materials revealed $66.36 \%$ and 64.25 $\%$ clot lysis of human blood, respectively. In the membrane stabilizing assay, the carbon tetrachloride soluble fraction inhibited $86.79 \%$ haemolysis of human RBCs in hypotonic solution-induced condition, while the aqueous soluble partitionate inhibited $92.39 \%$ haemolysis of RBCs in the heat-induced condition. The crude methanolic extract of bark of $N$. cadamba showed significant central and peripheral analgesic activity at both 200 and $400 \mathrm{mg} / \mathrm{kg}$ body weight, whereas its chloroform soluble fraction mildly inhibited the growth of test microorganisms. Therefore, our studies suggest that wild cinchona should be subjected to extensive phytopharmacological investigation.
\end{abstract}

Key words: Neolamarckia cadamba, antioxidant, DPPH, thrombolysis, analgesic

\section{Introduction}

Neolamarckia cadamba (Roxb.) (English name: Wild cinchona; Hindi name: Kadamb, Kadam) belongs to the family Rubiaceae. It is an evergreen, tropical tree native to South and Southeast Asia with scented orange flowers in dense globe-shaped clusters. The flowers are used in perfumes (Kirtikar et al., 1999). Bark of the plant is used in fever, inflammation, cough, vomiting, diarrhoea, diabetes, burning sensation, wounds, ulcers and snake-bite. The bark is also used for its significant diuretic and laxative property (Patel et al., 2008).

Previous phytochemical investigations of $N$. cadamba led to the isolation of cinchotannic acid, quixotic, cadambagenic acids, quinovic acid, saponins, steroids, alkaloids, one new secoiridoid, 3'-Ocaffeoylsweroside and two new phenolic apioglucosides, kelampayoside A and kelampayoside B (Prajapati et al., 2007).

As part of our investigations on medicinal plants of Bangladesh (Sikder et al., 2011, Tahia et al., 2014), the crude methanol extract of bark of $N$. cadamba as well as its organic and aqueous soluble fractions were studied for antioxidant potential in terms of total phenolic content and free radical scavenging, cytotoxic, thrombolytic, membrane stabilizing, antimicrobial and analgesic activities for the first time and we, here in, report the results of our preliminary investigations. 


\section{Materials and Methods}

Collection of plant materials and extraction: The bark of N. cadamba was collected in April 2015. Voucher specimen (Accession no: 34976) for the plant have been maintained in Bangladesh National Herbarium, Dhaka, Bangladesh for future reference.

The collected bark was cleaned, sun dried and pulverized. The powdered material $(500 \mathrm{~g})$ was soaked in 2.0 liters of methanol at room temperature for 7 days. The extracts were filtered through fresh cotton bed and finally with Whatman filter paper number 1 . The filtrate was concentrated with a rotary evaporator at reduced temperature and pressure. An aliquot $(5 \mathrm{~g})$ of each of the concentrated methanol extract was fractionated by the modified Kupchan partitioning protocol (Vanwagenen et al., 1993) and the resultant partitionates were evaporated to dryness to yield pet-ether (PESF), carbon tetrachloride (CTCSF), chloroform (CSF) and aqueous (AQSF) soluble materials (Table 1). The residues were then stored in a refrigerator until further use.

\section{Drugs and Chemicals}

Acetic acid (Merck, Germany), Tween-80 (BDH Chemicals,UK), normal saline solution (Beximco Infusion Ltd., Bangladesh), Morphine (Gonoshastho Pharmaceuticals), Diclofenac sodium, and Glibenclamide were used as standards. The extractives of the plant were dissolved in $1 \%$ Tween 80 and subsequently in $0.9 \%$ normal saline separately at a concentration of $10 \mathrm{mg} / \mathrm{ml}$ and the administered dose was according to the weight of the mice.

\section{Animal}

Swiss-albino mice of either sex aged 4-5 weeks, average weight $20-25 \mathrm{~g}$ were used for the experiment. The procedures in this study for animal handling were performed in accordance with the Animal Resources Branch of the International Center for Diarrheal Disease and Research, Bangladesh (ICDDR, B). All efforts were made to minimize sufferings of the animals and to reduce the number of animals used in the experiments. They were kept in standard environmental condition (at $24.0 \pm 1{ }^{\circ} \mathrm{C}$ temperature and 55-65\%

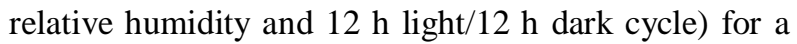
week for adaptation after their purchase and fed with rodent feed purchased from ICDDR,B and water ad libitum.

Total phenolic content: The total phenolic content of the extractives was determined with Folin-Ciocalteau reagent by using the method developed by Harbertson and Spayd, 2006.

Table 1. Kupchan partitionates of N. cadamba bark.

\begin{tabular}{ll}
\hline Crude extract/ Fractions & Bark (gm) \\
\hline ME & 5.00 \\
PESF & 0.65 \\
CTCSF & 0.75 \\
CSF & 0.30 \\
AQSF & 2.20 \\
\hline
\end{tabular}

$\mathrm{ME}=$ Methanolic crude extract, $\mathrm{PESF}=$ Pet-ether soluble fraction, $\mathrm{CTCSF}=$ Carbon tetrachloride soluble fraction, $\mathrm{CSF}=$ Chloroform soluble fraction, $\mathrm{AQSF}=$ Aqueous soluble fraction.

$D P P H$ free radical scavenging assay: Following the method developed by Brand-Williams et al., 1995 the antioxidant activity of the test samples was assessed by evaluating the scavenging activities of the stable 1, 1diphenyl-2-picrylhydrazyl (DPPH) free radical by using synthetic antioxidants, butylated hydroxytoluene (BHT) and ascorbic acid as reference standards.

Brine shrimp lethality bioassay: This technique was applied for the determination of general toxic properties of the dimethylsulfoxide (DMSO) solution of plant extractives against Artemia salina in a single day assay by using vincristine sulphate as positive control (Meyer et al., 1982).

Thrombolytic activity: The method developed by Prasad and Harbertson 2007, was used to determine the thombolytic activity using streptokinase (SK) as positive control.

Membrane stabilizing activity: The membrane stabilizing activity of the extractives was evaluated by the inhibition of heat- and hypotonic solution-induced haemolysis of human erythrocytes following the method developed by Omale et al., 2008.

Antimicrobial screening: Antimicrobial activity was determined by the disc diffusion method (Bauer et al., 1966) 
Central analgesic activity: Evaluation of central analgesic activity was carried by tail immersion method using Morphine as positive control. A constant heat stress was applied to rat tail, which acts as pain stimulus. When the stimulus exceeded the threshold, rat showed quick withdrawal of its tail. Time taken by the rat to withdraw the tail is termed as tail immersion time. Analgesic compounds elongate this responding time which was recorded to observe central analgesic action.

Peripheral analgesic activity: Peripheral analgesic activity was evaluated by formalin induced method (Pourmotabbed et al., 2001)

Statistical analysis: For all bioassays, three replicates of each sample were used for statistical analysis and the values are reported as mean \pm SD.

\section{Results and Discussion}

The crude methanol extract of bark of $N$. cadamba as well as its Kupchan partitionates were evaluated for antioxidant properties through total phenolic content, free radical scavenging capacity and cytotoxic, thrombolytic, membrane stabilizing, antimicrobial, and analgesic activities.

In the DPPH free radical scavenging assay, the pet ether soluble fraction of bark of $N$. cadamba revealed maximum free radical scavenging activity having $\mathrm{IC}_{50}$ value of $60.46 \pm 0.88 \mu \mathrm{g} / \mathrm{ml}$ while standard ascorbic acid showed $\mathrm{IC}_{50}$ value of $5.81 \pm 0.21 \mu \mathrm{g} / \mathrm{ml}$ (Table 2).

The total phenolic content of the extractives of bark of $N$. cadamba was found in the range of $3.10 \pm$ 0.23 to $58.26 \pm 0.45 \mathrm{mg}$ of GAE$/ \mathrm{g}$ of extractives, with the highest amount of phenolics $(58.26 \pm 0.45 \mathrm{mg})$ being observed in the carbon tetra chloride soluble fraction (Table 2).

In the brine shrimp lethality bioassay, the carbon tetrachloride soluble fraction displayed the highest cytotoxic potential with $\mathrm{LC}_{50}$ value of $7.24 \pm 0.08$ $\mu \mathrm{g} / \mathrm{ml}$, as compared to vincristine sulphate with $\mathrm{LC}_{50}$ of $0.45 \pm 0.01 \mu \mathrm{g} / \mathrm{ml}$ (Table 2).

The extractives of bark of $N$. cadamba were assayed for thrombolytic activity to determine the ability of clot lysis. Addition of $100 \mu \mathrm{l}$ streptokinase (SK), a positive control (30,000 I.U.) to the clots of human blood and subsequent incubation for 90 minutes at $37^{\circ} \mathrm{C}$ showed $65.88 \%$ lysis of the clot as compared to distilled water showing a negligible lysis of clot (3.74\%). In this study, the carbon tetrachloride soluble materials showed highest thrombolytic activity of 66.36 $\pm 0.88 \%$ (Table 2).

Table 2. Total phenolic content, free radical scavenging, cytotoxic and thrombolytic activities of N. cadamba.

\begin{tabular}{lccccc}
\hline Plant & $\begin{array}{c}\text { Sample/ } \\
\text { Standard }\end{array}$ & $\begin{array}{c}\text { Total phenolic } \\
\text { content (mg of } \\
\text { GAE/gm of extract) }\end{array}$ & $\begin{array}{c}\text { DPPH free radical } \\
\text { scavenging activity } \\
\left(\mathrm{IC}_{50} \mu \mathrm{g} / \mathrm{ml}\right)\end{array}$ & $\begin{array}{c}\text { Cytotoxicity } \\
(\mathrm{LC} 50 \mu \mathrm{g} / \mathrm{ml})\end{array}$ & \% Clot lysis \\
\hline Bark & ME & $3.10 \pm 0.23$ & $113.56 \pm 0.43$ & $19.0 \pm 0.45$ & $59.84 \pm 0.33$ \\
& PESF & $44.06 \pm 0.23$ & $60.46 \pm 0.23$ & $7.89 \pm 0.08$ & $66.36 \pm 0.23$ \\
& CTCSF & $58.26 \pm 0.45$ & $78.58 \pm 0.76$ & $7.24 \pm 0.62$ & $11.93 \pm 0.11$ \\
& CSF & $7.28 \pm 0.56$ & $75.20 \pm 0.65$ & $8.33 \pm 0.44$ & $34.04 \pm 0.23$ \\
\multirow{5}{*}{ Standards } & AQSF & $10.0 \pm 0.33$ & $171.20 \pm 0.88$ & $13.37 \pm 0.59$ & $64.25 \pm 0.56$ \\
& VS & - & - & $0.45 \pm 0.01$ & \\
& BHT & - & $27.70 \pm 0.54$ & - & \\
& Ascorbic acid & - & $5.81 \pm 0.21$ & - & $3.74 \pm 0.55$ \\
& Blank & & & & $65.88 \pm 1.08$ \\
\hline
\end{tabular}

$\mathrm{ME}=$ Methanolic crude extract, $\mathrm{PESF}=$ Pet-ether soluble fraction, $\mathrm{CTCSF}=\mathrm{Carbon}$ tetrachloride soluble fraction, $\mathrm{CSF}=$ Chloroform soluble fraction, $\mathrm{AQSF}=$ Aqueous soluble fraction, $\mathrm{BHT}=$ Butylated hydroxytoluene, $\mathrm{VS}=\mathrm{Vincristine}$ sulfate, $\mathrm{SK}=$ Streptokinase 
Table 3. Percent inhibition of hypotonic solution- and heat-induced hemolysis of erythrocyte membrane by bark of $N$. cadamba.

\begin{tabular}{lll}
\hline Sample & \multicolumn{2}{c}{ \% Inhibition } \\
& Hypnotic solution-induced & Heat-induced \\
\hline ME & $86.26 \pm 0.66$ & $90.57 \pm 0.23$ \\
PESF & $80.79 \pm 0.55$ & $28.82 \pm 0.43$ \\
CTCSF & $86.79 \pm 0.84$ & $34.89 \pm 0.56$ \\
CSF & $10.47 \pm 0.67$ & $2.15 \pm 0.44$ \\
AQSF & $82.61 \pm 0.84$ & $92.39 \pm 0.21$ \\
Acetyl salicylic acid & $72.2 \pm 0.47$ & $42.2 \pm 0.23$ \\
\hline
\end{tabular}

Table 4. Antibacterial activity of bark of N. cadamba.

\begin{tabular}{|c|c|c|c|c|c|c|}
\hline \multirow[t]{2}{*}{ Test microorganisms } & \multicolumn{6}{|c|}{ Diameter of zone of inhibition (mm) } \\
\hline & ME & PESF & CTCSF & CSF & AQSF & Ciprofloxacin \\
\hline Bacillus cereus & - & - & 8.0 & 7.0 & - & 40.0 \\
\hline B. megaterium & - & - & - & - & - & - \\
\hline B. subtilis & - & - & - & - & - & 40.0 \\
\hline Staphylococcus aureus & - & - & - & 7.0 & 9.0 & 50.0 \\
\hline Sarcina lutea & - & - & - & - & - & 53.0 \\
\hline Escherichia coli & - & 10.0 & - & 8.0 & - & 47.0 \\
\hline Pseudomonas aeruginosa & - & 7.0 & 8.0 & 6.0 & 8.0 & 51.0 \\
\hline Salmonella paratyphi & - & 11.0 & 8.0 & 7.0 & 9.0 & 49.0 \\
\hline S. typhi & - & 11.0 & 7.0 & 7.0 & - & 47.0 \\
\hline Shigella boydii & - & - & - & - & 6.0 & 47.0 \\
\hline Sh. dysenteriae & - & - & 8.0 & 7.0 & 9.0 & 45.0 \\
\hline Vibrio mimicus & - & 9.0 & 7.0 & 9.0 & 9.0 & 45.0 \\
\hline V. parahemolyticus & - & - & - & - & - & 48.0 \\
\hline
\end{tabular}

Table 5. Central analgesic activity of $N$. cadamba.

\begin{tabular}{|c|c|c|c|c|c|c|}
\hline Sample & $\begin{array}{c}\text { Average } \\
\text { (immersion time } \\
\text { count) } \pm \mathrm{SD}\end{array}$ & $\%$ elongation & $\begin{array}{c}\text { Average } \\
\text { (immersion } \\
\text { time count) } \pm \\
\text { SD }\end{array}$ & $\%$ elongation & $\begin{array}{c}\text { Average } \\
\text { (immersion } \\
\text { time count) } \pm \\
\text { SD }\end{array}$ & $\%$ elongation \\
\hline & \multicolumn{2}{|c|}{ After $30 \mathrm{~min}$} & \multicolumn{2}{|c|}{ After $60 \mathrm{~min}$} & \multicolumn{2}{|c|}{ After 90 min } \\
\hline CTL & $4.23 \pm 0.23$ & & & & & \\
\hline STD & $8.22 \pm 0.31$ & 94.56 & & & & \\
\hline ME 1 & $7.88 \pm 0.21$ & 86.22 & $5.30 \pm 0.22$ & 25.30 & $7.33 \pm 0.11$ & 73.29 \\
\hline ME 2 & $7.03 \pm 0.33$ & 66.26 & $6.61 \pm 0.13$ & 56.26 & $6.67 \pm 0.14$ & 57.68 \\
\hline
\end{tabular}

ME 1 = methanolic crude extract at $200 \mathrm{mg} / \mathrm{kg}$ body weight

$\mathrm{CTL}=$ control

ME $2=$ methanolic crude extract at $400 \mathrm{mg} / \mathrm{kg}$ body weight

$\mathrm{STD}=$ standard 
Table 6. Peripheral analgesic activity of methanol extract of $N$. cadamba.

\begin{tabular}{lccc}
\hline & Sample & Average writhing count \pm SD & \% Inhibition \\
\hline Bark & CTL & $19.5 \pm 0.23$ & - \\
& STD & $5.01 \pm 0.33$ & 74.36 \\
& ME 1 & $8.25 \pm 0.45$ & 57.69 \\
& ME 2 & $9.75 \pm 0.22$ & 50.03 \\
\hline
\end{tabular}

In the membrane stabilizing activity assay, the extractives significantly protected the lysis of human erythrocyte membrane induced by heat- and hypotonicsolution, when compared to the standard acetyl salicylic acid. The carbon tetrachloride soluble partitionates of methanol extract inhibited $86.79 \%$ haemolysis of RBCs in hypotonic solution-induced condition, while in the heat-induced condition; the aqueous soluble fraction inhibited $92.39 \%$ haemolysis of RBCs (Table 3).

Among all the extractives of bark of $N$. cadamba, the methanolic extract, at a concentration of $400 \mu \mathrm{g} /$ disc, exhibited mild antimicrobial activity. The inhibitory activity of the extractives was compared with ciprofloxacin as standard (Table 4).

The methanolic crude extract of bark of $N$. cadamba showed significant central analgesic activity at 400 $\mathrm{mg} / \mathrm{kg}$ body weight after 30- 60- and 90- minutes of administration (Table 5). Extractives of bark showed statistically significant peripheral analgesic activity at both doses (200- and 400- $\mathrm{mg} / \mathrm{kg}$ body weight) with writhing inhibition of $57.69 \%$ and $50.03 \%$, respectively (Table 6).

\section{Conclusion}

The results of above investigations suggest that the bark of $N$. cadamba have significant free radical scavenging, cytotoxic, membrane stabilizing, thrombolytic, as well as central and peripheral analgesic activities. However, the plant exhibited mild antimicrobial potential. The bark of $N$. cadamba is traditionally used for inflammation, fever, pain and other conditions. Our investigations justify the medicinal uses of this plant species. Further comprehensive phytopharmacological studies are required to isolate the bioactive molecules from this plant.

\section{References}

Bauer, A.W., Kirby, W.M.M., Sheriss, J.C. and Turck, M. 1966. Antibiotic susceptibility testing by standardised single method. Am. J. Clin. Pathol. 45, 493-496.

Brand-Williams, W., Cuvelier, M.E. and Berset, C. 1995. Use of free radical method to evaluate antioxidant activity. Lebensm. Wiss. Technol. 28, 25-30.

Harbertson, J. and Spayd, S. 2006. Measuring phenolics in the winery. Am. J. Enol. Vitic. 57, 280-288.

K.R. Kirtikar and B.D. Basu. 1999. Indian medicinal plants. Lalit mohan basu publishers, Allahabad, 2, 1250-1252.

Meyer, B.N., Ferringni, N.R., Puam, J.E., Lacobsen, L.B., Nichols, D.E. and McLaughlin, J.L. 1982. Brine shrimp: a convenient general bioassay for active constituents. Planta Med. 45, 31-32.

Omale, J. and Okafor, P.N. 2008. Comparative antioxidant capacity, membrane stabilization, polyphenols composition and cytotoxicity of the leaf and stem of Cissus multistriata. Afr. J. Biotechnol. 7, 3129-3133.

Patel, D. and Kumar, V. 2008. Int. J. Green Pharm. 1, 26-27

Pourmotabbed, A., Farshchi, A., Ghiasi, G. and Khatabi, P.M. 2001. Analgesic and anti-inflammatory activity of Teucrium chamaedrys leaves aqueous extract in male rats. Soc. Sci. Med. 34, 735-746.

Prajapati, Purohit, Sharma and Kumar, A. 2007. A handbook of medicinal plants: A complete source book. Agrobios (India) publisher, Jodhpur, pp. 52-53.

Prasad, S., Kashyap, R.S., Deopujari, J.Y., Purohit, H.J., Taori, G.M. and Daginawala, H.F. 2007. Effect of Fagonia arabica (Dhamasa) on in vitro thrombolysis, BMC Complement. Alternat. Med. 7, 36

Sikder, M.A., Hossian, A.K.M.N., Siddique, A.B., Ahmed, M., Kaisar, M.A. and Rashid, M.A. 2011. In vitro antimicrobial screening of four reputed Bangladeshi medicinal plants. Pharmacog. J. 3, 72-75.

Tahia, F., Sikder, M. A., Sayeed, M.A. and Rashid, M.A. 2014. Bioactivities of Murraya koenigii (Linn.) and Adina cordifolia (Roxb.). Bang. Pharm. J. 18, 25-29.

Vanwagenen, B.C., Larsen, R., Cardellina, J.H., Randazzo, D., Lidert, Z.C. and Swithenbank, C. 1993. Ulosantoin, a potent insecticide from the sponge Ulosa ruetzleri. J. Org. Chem. 58, 335-337. 